\title{
Relationship Between Proliferative Breast Lesions and Breast Cancer Risk Factors
}

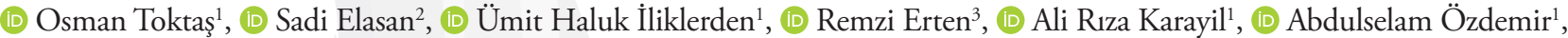 \\ (D) Firat Aslan ${ }^{1}$, (D) Serhat Binici ${ }^{1}$, (D) İbrahim Özalp ${ }^{1}$, (D) Enes Şentürk ${ }^{1}$ \\ ${ }^{1}$ Department of General Surgery, Van Yüzüncü Yıl University Faculty of Medicine, Van, Turkey \\ ${ }^{2}$ Department of Biostatistics, Van Yüzüncü Yıl University Faculty of Medicine, Van, Turkey \\ ${ }^{3}$ Department of Pathology, Van Yüzüncü Yıl University Faculty of Medicine, Van, Turkey
}

\begin{abstract}
Objective: The prognosis of breast cancer $(\mathrm{BC})$ is determined directly based on the stage of disease at the time of diagnosis. Proliferative breast lesions (PBLs) are an important risk factor for $\mathrm{BC}$ development. The risk of developing $\mathrm{BC}$ varies according to the presence of extent of proliferation in the breast lesions. We aimed to investigate the effect of BC risk factors on the PBLs in this study.

Materials and Methods: Patients who visited the surgical clinic of the university during the past 6 years who presented with PBLs with or without atypia by fine/core needle aspiration biopsy were included in this study. The relationship between PBLs and BC risk factors such as the age, mass size, Body Mass index (BMI), smoking, sports activity, BC family history, the use of hormone replacement therapy, number of pregnancies, and the duration of breastfeeding were compared.

Results: A total of $74(96.1 \%)$ of all patients were women and three were men. The median age of the patients was 38 (range: 19-74) years; the cut-off value of age was 35.5 years. The mean age of patients with PBL-with atypia (PBL-WA) was higher $(\mathrm{p}=0.005)$ in the malignant group based on the final pathology and radiological imaging features (for both, $\mathrm{p}<0.001$ ). The mean size of the mass was large at $2.53 \pm 1.33(1-6) \mathrm{cm}$; and the cut-off value of the tumor size was $2.5 \mathrm{~cm}$. The mean size was greater in the PBL-WA patients $(\mathrm{p}=0.171)$ in the malignant group based on the final pathology and radiological characteristic (respectively, $\mathrm{p}=0.004$ and $\mathrm{p}=0.016)$. The mean BMI was $26.8 \pm 4.4 \mathrm{~kg} / \mathrm{m}^{2}(18.8-35.1)$ and the cut-off value was $25.4 \mathrm{~kg} / \mathrm{m}^{2}$. BMI was greater in the PBL-WA group and in the malignant group based on the final pathology (respectively, $\mathrm{p}=0.002$ and $\mathrm{p}=0.001$ ). Smoking was positive in $66.2 \%$ ( $\mathrm{n}=51$ ) of the patients, and it was high in the PBL-WA patients $(\mathrm{p}=0.001)$. The percentage of patients with no sports activity was $63.6 \%$ ( $\mathrm{n}=49$ ), while it was $20.8 \%$ $(\mathrm{n}=16)$ for those with once a week sports activity and $15.6 \%(\mathrm{n}=12)$ for those with twice a week activity. There was family history of BC in $16.9 \%(\mathrm{n}=13)$ of all patients. The number of positive cases of family history of $\mathrm{BC}$ was greater in the malignant group $(\mathrm{p}=0.001)$. Hormone replacement therapy was recorded in $11.7 \%(\mathrm{n}=9)$ of the patients. The mean numbers of pregnancies $(2.1 \pm 2.4)$ and breastfeeding duration $(32.5 \pm 37.4$ months) were low in the benign groups due to the relatively lower average age of the patients.

Conclusion: Based on our analysis, age is an extremely important aspect for assessing PBLs. The age of the patient was statistically significantly greater in the patients with malignant lesions in all groups. The factors lesion size, BMI, smoking habit, and BC family history were also more frequent in the malignant groups. The rate of sports activity was lower in the malignant groups. Thus, it is necessary to evaluate patients individually when evaluating PBLs. It is recommended to evaluate PBLs together with BC risk factors for the better understanding.
\end{abstract}

Keywords: Breast cancer, benign breast disease, proliferative breast lesion with atypia or without atypia

Cite this article as: Toktaş O, Elasan S, İliklerden ÜH, Erten R, Karayil AR, Özdemir A, Aslan F, Binici S, Özalp İ, Şentürk E. Relationship Between Proliferative Breast Lesions and Breast Cancer Risk Factors. Eur J Breast Health 2021; 17(1): 15-20.

\section{Introduction}

Although the relationship between proliferative breast lesions (PBLs) and breast cancer (BC) has been discussed, PBLs are known as an important risk group in $\mathrm{BC}$ development. The risk of $\mathrm{BC}$ increases according to the type of benign breast lesions. While there is no risk of $\mathrm{BC}$ in nonPBLs, this risk doubles on an average for PBL-without atypia (PBL-WOA) patients and increases by 4-6 times in female PBL-with atypia (PBL-WA) patients. Although several studies have been performed on the classification of PBLs, there is only a limited number of studies that have investigated the relationship between PBLs and BC risk factors. Nevertheless, it remains unclear as to which lesions should be completely resected and which should be followed up (1-4). In this study, we aimed to investigate the relationship between the final pathology outcomes of PBLs and other risk factors of BC.

\section{Corresponding Author: \\ Osman Toktaş; osmantoktas@windowslive.com}

This study was presented in the $15^{\text {th }}$ National Breast Diseases Congress, October 17th-20th, 2019 in Titanic Belek 


\section{Materials and Methods}

Patients who visited the surgical clinic of the university during the past 6 years and who with presented PBLs with or without atypia by fine/core needle aspiration biopsy were included in this study. Patients aged $<18$ years, whose file information could not be reached, and those without follow-up information were excluded from the study. Fibrocystic disease, fibroadenoma, normal breast tissue, and inflammation were classified as benign, and all cancer types were classified as malignant. We assessed the relationship between PBLs and BC risk factors such as the age, mass size, Body Mass Index (BMI), smoking habit, sports activity, $\mathrm{BC}$ family history, use of hormone replacement therapy, the number of pregnancies, and the duration of breastfeeding.

\section{Statistical analysis}

The sample size was calculated with Power (least) \%80 and Type1 error 0.05 for all variables. The Kolmogorov-Smirnov $(n>50)$ and Skewness-Kurtosis tests were applied to examine whether the measurements in the study were normally distributed. Accordingly, parametric tests were applied since the measurements were normally distributed. In this study, descriptive statistics for continuous variables were expressed as the mean, standard deviation, and the minimum and maximum values. Categorical variables were described as number (n) and percentage (\%). Independent t-test and one-way analysis of variance (ANOVA) tests were performed to compare the group mean values in continuous variables. Following the ANOVA, the Duncan post-hoc test was used to determine the different groups. Pearson's correlation coefficients were calculated to determine the relationship among the variables. The chi-square test was employed to determine the relationship between the groups and among the categorical variables. Statistical significance level was considered as $5 \%$ in the calculations, and SPSS (IBM SPSS for Windows, ver.23) statistical package program was used for the calculations.

\section{Results}

The medical files of 77 cases were retrospectively reviewed. The descriptive properties are shown in Table 1 . The median age of the

\section{Table 1. Descriptive properties of the patients}

\begin{tabular}{llc} 
& & $\mathbf{n}(\%)$ \\
Sex & M & $3(3.9)$ \\
& F & $74(96.1)$ \\
Radiological features & Benign & $51(66.2)$ \\
& Malignant & $26(33.8)$ \\
Side & Right & $31(40.3)$ \\
Fine/core needle & Left & $46(59.7)$ \\
aspiration biopsy & PBL-WA & $61(79.2)$ \\
Intervention & PBL-WOA & $16(20.8)$ \\
& Surgery & $65(84.4)$ \\
Final pathology & Follow-up & $12(15.6)$ \\
& Benign & $53(68.8)$ \\
\hline
\end{tabular}

PBL-WA: Proliferative breast lesions with atypia; PBL-WOA: Proliferative breast lesions without atypia; M: Male; F: Female; n: Number patients was 38 (range: 19-74) years. The cut-off value of age was 35.5 years. The mean age of the PBL-WA patients was $40.98 \pm 12.74$ years and that of PBL-WOA patients was $30.75 \pm 12.36$ years $(\mathrm{p}=0.005)$. The mean age as per the final pathology was $33.66 \pm 10.17$ years for the benign group and $50.33 \pm 12.15$ years for the malignant group $(\mathrm{p}<0.001)$. The mean age as per the radiology features was $35.12 \pm 11.6$ years for the benign group and $46.19 \pm 13.46$ years for the malignant group $(\mathrm{p}<0.001)$. The mean age of the PBL-WA patients in the benign final pathology group was $34.89 \pm 8.84$, while it was $51.04 \pm 11.90$ years for the PBL-WA patients in the malignant final pathology group. In both the groups, the mean age was greater in the malignant group than in the benign groups (Table 2).

The mean size of the mass was $2.53 \pm 1.33(1-6) \mathrm{cm}$, and the cut-off value of the mass size was $2.5 \mathrm{~cm}$. The mean mass size for the PBL-WA patients was $2.64 \pm 1.37 \mathrm{~cm}$, while it was $2.13 \pm 1.15 \mathrm{~cm}$ for the PBLWOA patients $(\mathrm{p}=0.171)$. The mass size as per the final pathology was $2.25 \pm 1.22 \mathrm{~cm}$ in the benign group and $3.17 \pm 1.37 \mathrm{~cm}$ in the malignant group ( $\mathrm{p}=0.004)$. The mean mass size was greater of the malignant lesions as per the fine/core needle aspiration biopsy, final pathology, and radiological imaging. The mean BMI value was $26.8 \pm 4.4 \mathrm{~kg} / \mathrm{m}^{2}$ (range: 18.8-35.1), and the cut-off value was 25.4. The corresponding value was $27.6 \pm 4.2 \mathrm{~kg} / \mathrm{m}^{2}$ for the PBL-WA patients and $23.8 \pm 3.9$ $\mathrm{kg} / \mathrm{m}^{2}$ for the PBL-WOA patients $(\mathrm{p}=0.002)$. BMI as per the final pathology was $25.1 \pm 3.8 \mathrm{~kg} / \mathrm{m}^{2}$ in the benign group and $30.6 \pm 3.0 \mathrm{~kg} /$ $\mathrm{m}^{2}$ in the malignant group $(\mathrm{p}=0.001)$. The mean number of children was 3.08 $\pm 2.1(0-8)$ in the PBL-WA group and 2.1 $\pm 2.4(0-7)$ in the PBL-WOA group $(\mathrm{p}=0.156)$. The mean overall total duration of breastfeeding was $51.8 \pm 41.7$ months (0-156), and it was $56.9 \pm 41.5$ months in the PBL-WA group and $32.5 \pm 37.4$ months in the PBLWOA groups $(\mathrm{p}=0.036)$. The cause of the lower number of children in the benign group was the lower patient age (Table 2).

Smoking habit was reported in $66.2 \%(n=51)$ of the patients. A total of $48(94.1 \%)$ patients were included in the PBL-WA group and 3 (5.9\%) patients in the PBL-WOA group ( $\mathrm{p}=0.001)$. In the PBL-WA group, $68.9 \%(\mathrm{n}=42)$ of the patients had no history of sports activities, $16.4 \%(\mathrm{n}=10)$ had a history of sports activities once a week, and $14.8 \%$ $(n=9)$ had a history of sports activities twice a week. In the PBL-WOA patients, $43.8 \%(n=7)$ of the patients had no history of indulging in sports activities, $37.5 \%(n=6)$ of the patients had a history of indulging in sports activities once a week, and $18.8 \%(n=3)$ of the patients had a history of indulging in sports activities twice a week $(\mathrm{p}=0.129)$. In addition, $83.1 \%(\mathrm{n}=64)$ of the patients had no BC family history, while $16.9 \%(n=13)$ had a BC family history. Moreover, as per the final pathology, there were four $(30.7 \%)$ patients in the benign group and nine $(69.3 \%)$ patients in the malignant group $(\mathrm{p}=0.001)$. In addition, $88.3 \%(\mathrm{n}=68)$ of the patients did not use hormone replacement therapy (HRT), while $11.7 \%(n=9)$ did (Table 3).

The malignancy rate of the PBL-WA patients was $37.7 \%$ ( $n=23)$, while it was $6.3 \%(n=1)$ in the PBL-WOA patients as per the final pathology $(\mathrm{p}=0.016)$. Breast-conserving surgery or mastectomy and sentinel lymph node dissection was performed in 19 (79.1\%) patients, axillar lymph node dissection in five (20.9\%)patients, and modified radical mastectomy in five $(20.9 \%)$ patients. The positive predictive value for malignant lesions in the PBLs was $90.2 \%$, negative predictive value was $73 \%$, and accuracy was $84.4 \%$ for radiology $(\mathrm{p}=0.001$ ). Twelve patients $(15.6 \%)$ did not undergo surgery, and the follow-up time was $4.72 \pm 2.49$ years. Six of these patients $(50 \%)$ had PBL-WOA patients and the other six $(50 \%)$ were PBL-WA patients. The mean age of the 
Table 2. Comparison of the results of proliferative breast lesions according to the variables

\begin{tabular}{|c|c|c|c|c|}
\hline & Variables & \multicolumn{2}{|c|}{ Mean \pm SD } & p-value \\
\hline \multirow{12}{*}{ Mean age } & Overall mean age & \multicolumn{2}{|c|}{$38.86 \pm 13.26$} & \multirow{4}{*}{$<0.001$} \\
\hline & Cut-off value & \multicolumn{2}{|c|}{$35.5 \mathrm{~cm}$} & \\
\hline & \multirow{2}{*}{ Radiological features } & Benign & $35.12 \pm 11.6$ & \\
\hline & & Malignant & $46.19 \pm 13.46$ & \\
\hline & \multirow{2}{*}{$\begin{array}{l}\text { Fine/core needle } \\
\text { aspiration biopsy }\end{array}$} & PBL-WOA & $30.75 \pm 12.36$ & \multirow{2}{*}{0.005} \\
\hline & & PBL-WA & $40.98 \pm 12.74$ & \\
\hline & \multirow{2}{*}{ Final pathology } & Benign & $33.66 \pm 10.17$ & \multirow{2}{*}{$<0.001$} \\
\hline & & Malignant & $50.33 \pm 12.15$ & \\
\hline & \multirow{2}{*}{ PBL-WA } & Benign & $34.89 \pm 8.84$ & \multirow{2}{*}{$<0.001$} \\
\hline & & Malignant & $51.04 \pm 11.90$ & \\
\hline & \multirow{2}{*}{ PBL-WOA } & Benign & $30.53 \pm 12.77$ & \multirow{2}{*}{0.268} \\
\hline & & Malignant & $34.00 \pm 12.77$ & \\
\hline \multirow{8}{*}{ Size of mass } & Overall mean size & $2.53 \pm 1.33$ & & \multirow{4}{*}{0.016} \\
\hline & Cut-off value & $2.5 \mathrm{~cm}$ & & \\
\hline & \multirow{2}{*}{ Radiological features } & Benign & $2.27 \pm 1.13$ & \\
\hline & & Malignant & $3.04 \pm 1.56$ & \\
\hline & Fine/core needle & PBL-WOA & $2.13 \pm 1.15$ & 171 \\
\hline & aspiration biopsy & PBL-WA & $2.64 \pm 1.37$ & 0.171 \\
\hline & \multirow{2}{*}{ Final pathology } & Benign & $2.25 \pm 1.22$ & \multirow{2}{*}{0.004} \\
\hline & & Malignant & $3.17 \pm 1.37$ & \\
\hline \multirow{6}{*}{ BMI (kg/m²) } & Overall mean BMI & $26.8 \pm 4.4$ & & \\
\hline & Cut-off value & 25.4 & & \\
\hline & Fine/core needle & PBL-WOA & $23.8 \pm 3.9$ & \multirow{2}{*}{0.002} \\
\hline & aspiration biopsy & PBL-WA & $27.6 \pm 4.2$ & \\
\hline & \multirow{2}{*}{ Final pathology } & Benign & $25.1 \pm 3.8$ & \multirow{2}{*}{0.001} \\
\hline & & Malignant & $30.6 \pm 3$ & \\
\hline \multirow{3}{*}{ Number of pregnancies } & Mean number pregnancies & $3.08 \pm 2.1$ & & \multirow{4}{*}{0.156} \\
\hline & Fine/core needle & PBL-WOA & $2.1 \pm 2.4$ & \\
\hline & aspiration biopsy & PBL-WA & $3.08 \pm 2.1$ & \\
\hline \multirow{3}{*}{ Mean breastfeeding time } & Overall mean breastfeeding time & $51.8 \pm 41.7$ & & \\
\hline & Fine/core needle & PBL-WOA & $32.5 \pm 37.4$ & \multirow{2}{*}{0.036} \\
\hline & aspiration biopsy & PBL-WA & $56.9 \pm 41.5$ & \\
\hline
\end{tabular}

patients was $34.75 \pm 10.29$ years, and the mean size was $1.67 \pm 0.78 \mathrm{~cm}$. Both the mean age and size were lower than the cut-off value. None of them were diagnosed with malignancy during the follow-up time.

\section{Discussion and Conclusion}

Benign breast lesion can be classified as non-PBLs, PBL-WOA, and PBL-WA. These lesions were detected more frequently because of the widespread use of mammography, which makes it is important to identify patients at risk for BC. PBLs, especially containing atypia, are the risk factors for both non-invasive and invasive $\mathrm{BC}$. In the PBL-WOA patients (e.g., complex fibroadenoma, moderate or floride hyperplasia, sclerosing adenosis, and intraductal papilloma), there is a slight increased risk for BC [relative risk (RR): 1.3-2]. The risk is greater in PBL-WA patients (such as atypical lobular hyperplasia and atypical ductal hyperplasia; RR: 4-6). When the atypia is multifocal, the risk increases by 10 times (4-6). In our study, the rate of malignancy of PBL-WA patients was greater than that of PBL-WOA patients as per the final pathology.

While the relationship of PBL-WOA and BC does not change with age, it is stronger in postmenopausal patients $(6,7)$. In our study, however, we observed a significant effect of age on the type of PBLs. The mean age of the PBL-WA patients was $40.98 \pm 12.74$ years and that 
Table 3. Comparison of the results of proliferative breast lesions by risk factors

\begin{tabular}{|c|c|c|c|c|}
\hline & Factors & \multicolumn{2}{|c|}{ n (\%) } & p-value \\
\hline \multirow{5}{*}{ Smoking } & Have been smoking & & & \multirow{3}{*}{0.001} \\
\hline & Fine/core needle & PBL-WOA & $18.8 \%$ & \\
\hline & aspiration biopsy & PBL-WA & $78.7 \%$ & \\
\hline & \multirow{2}{*}{ Final pathology } & Benign & $64.2 \%$ & \multirow{2}{*}{0.566} \\
\hline & & Malignant & $70.8 \%$ & \\
\hline \multirow{3}{*}{ Sports activity } & No sports activity & \multicolumn{2}{|c|}{$49(63.6 \%)$} & - \\
\hline & 1 day per week & \multicolumn{2}{|c|}{$16(20.8 \%)$} & - \\
\hline & 2 days per week & \multicolumn{2}{|c|}{$12(15.6 \%)$} & - \\
\hline \multirow{3}{*}{ Breast cancer family history } & Have been family history & \multicolumn{2}{|c|}{$13(16.9 \%)$} & - \\
\hline & & Benign & $7.5 \%$ & \multirow[b]{2}{*}{0.001} \\
\hline & Final pathology & Malignant & $37.5 \%$ & \\
\hline HRT & Positive HRT history & \multicolumn{2}{|c|}{$11.7 \%(9)$} & \\
\hline
\end{tabular}

PBL-WA: Proliferative breast lesions with atypia; PBL-WOA: Proliferative breast lesions without atypia; HRT: Hormone replacement therapy; n: Number

of the PBL-WOA patients was $30.75 \pm 12.36$ years $(\mathrm{p}=0.005)$. As per the final pathology, the mean age was $33.66 \pm 10.17$ years in the benign group and $50.33 \pm 12.15$ years in the malignant group $(\mathrm{p}<0.001)$. As the risk of $\mathrm{BC}$ increases with age, age was noted as an important factor in PBLs. Malignant lesions were recorded in the advanced age in both the groups (patients with PBL-WA and patients with malignant pathology result) (Figure 1).

Renshaw et al. (8) reported no correlation between the size of lesion and atypical ductal hyperplasia or ductal carcinoma in situ. However, the size of lesions diagnosed as carcinoma was significantly greater than that of lesions diagnosed as PBL-WA ( $\mathrm{p}<0.001)$. In our study, the mean pathological tumor size was $2.25 \pm 1.22 \mathrm{~cm}$ in the benign group and $3.17 \pm 1.37 \mathrm{~cm}$ in the malignant group $(\mathrm{p}=0.004)$. The size of the mass was larger in all malignant patients (Figure 2).

Several past epidemiological studies have shown that being overweight and/or obese, indicated by BMI in postmenopausal women, is a risk factor for BC development (9-11). BC is more common in obese women $\left(B M I>30 \mathrm{~kg} / \mathrm{m}^{2}\right)$ (12). When postmenopausal women lose $\geq 10 \mathrm{~kg}$, they are at a lesser risk than those who do not lose weight (7, 13). In our study, while the BMI was $27.6 \pm 4.2 \mathrm{~kg} / \mathrm{m}^{2}$ ( $\left.\mathrm{n}=61\right)$ for the PBL-WA patients, it was $23.8 \pm 3.9 \mathrm{~kg} / \mathrm{m}^{2}(\mathrm{n}=16)$ for the PBL-WOA

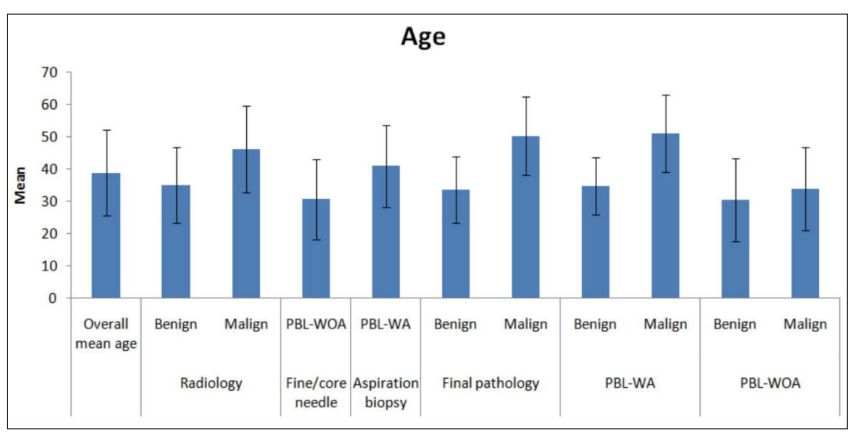

Figure 1. In all groups, the age was greater in patients with malignant lesions

PBL-WA: Proliferative breast lesions with atypia; PBL-WOA: Proliferative breast lesions without atypia patients $(\mathrm{p}=0.002)$. In addition, as per the final pathology, BMI was $25.1 \pm 3.8 \mathrm{~kg} / \mathrm{m}^{2}(\mathrm{n}=53)$ for the benign group and $30.6 \pm 3.0 \mathrm{~kg} / \mathrm{m}^{2}$ $(\mathrm{n}=24)$ for the malignant group $(\mathrm{p}=0.001)$ (Figure 3). Several studies have also shown that pregnancy and breastfeeding have a protective

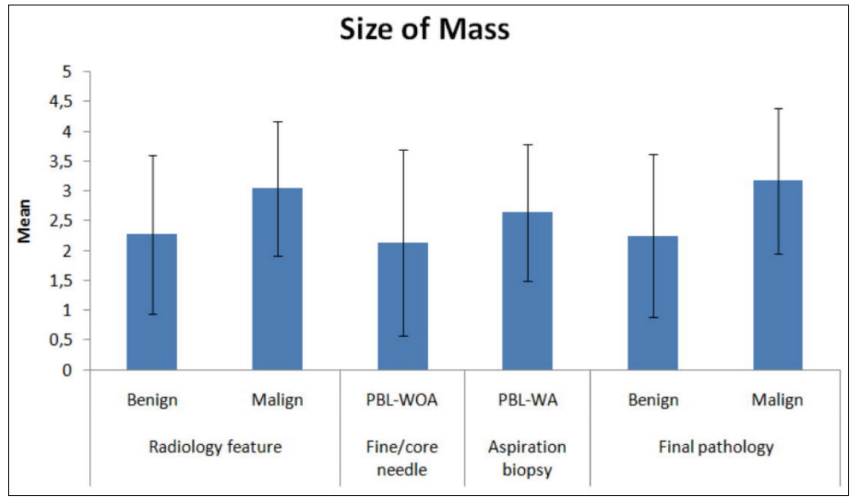

Figure 2. In all groups, the mass size was greater in patients with malignant lesions

PBL-WA: Proliferative breast lesions with atypia; PBL-WOA: Proliferative breast lesions without atypia

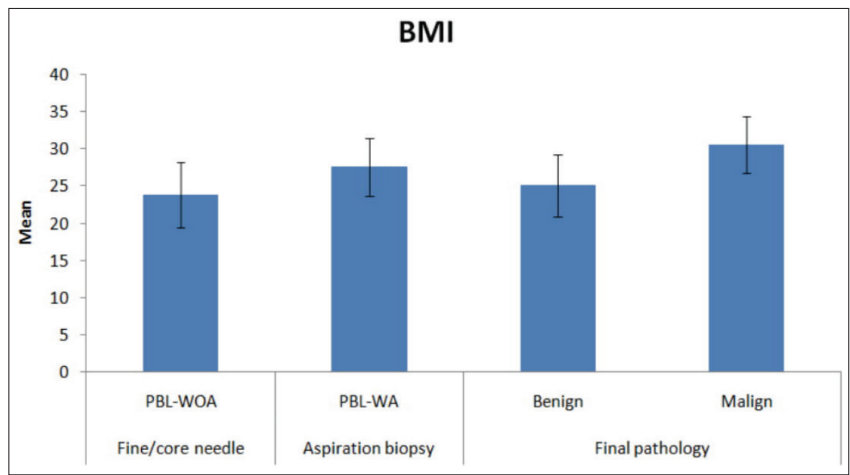

Figure 3. Body mass index was greater in patients with malignant lesions

PBL-WA: Proliferative breast lesions with atypia; PBL-WOA: Proliferative breast lesions without atypia; BMI: Body mass index 
effect against BC (14). In our study, the mean number of children and the total duration of breastfeeding were lower in the benign groups due to the young age of the patient. The relationship between smoking and $\mathrm{BC}$ is contradictory. Although very different results have been reported in the literature, it is believed to increase the risk associated with some other factors $(15,16)$. Positive smoking history was $78.7 \%(n=48)$ for the PBL-WA patients and $18.8 \%(\mathrm{n}=3)$ for the PBL-WOA patients $(\mathrm{p}=0.001)$ (Figure 4).

Increased physical activity, especially in premenopausal women, is associated with a reduced risk of BC (7). Lynch et al. (17) indicated an average of $25 \%$ reduction in BC risk among physically active women when compared with the least active women in a meta-analysis of 73 studies on the relationship between physical activity and BC. In our study, the percentage of patients with no sport activities was more in the malignant group than in the PBL-WA group as per the final pathology.

Patients with a family history showed a higher risk of developing BC, but the effect of PBLs with a family history has been discussed in the literature. The possibility of developing age-related BC in 10 years in women with a family history and proliferative breast disease is one in 2000 at the age of 20 years, one in 256 at 30, one in 67 at 40 , one in 39 at 50 , and one in 29 at $60(7,18,19)$. A family history of maternal $\mathrm{BC}$ has not been found to be related to the degree of atypia or fibrocystic breast disease in most hospital-population-based studies (20-22). The family history of BC has very little effect on the risk of developing BC in patients with non-PBLs; however, there is an 11fold increased risk in patients with PBLs presenting with atypia (23). In our study, the percentage of patients with BC family history was greater in the malignant group than in the PBL-WA group, as per the final pathology.

Both the World Health Organization and the One Million Women Study have revealed that women who received HRT had an increased risk of developing BC. however, as per epidemiological studies, no relationship has been established between the use of HRT and the risk of developing BC. Although a relative increase in risk of 1.24 was reported by a few large-scale studies, this relationship has not been revealed in the two recent studies (24-27). In our study, no statistically significant risk was noted between the use of HRT and the development of PBL-WA.

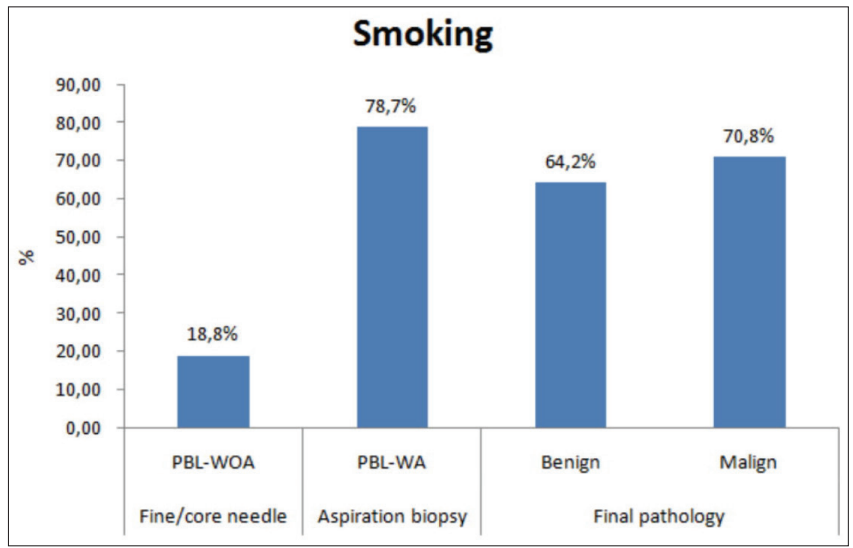

Figure 4. The smoking rate was significantly greater in the PBL-WA patients

PBL-WA: Proliferative breast lesions with atypia; PBL-WOA: Proliferative breast lesions without atypia
The limitation of the present study is that it was a single-center study with a smaller sample size.

In conclusion, our results indicate that age is an extremely important aspect in assessing PBLs. The patient age was statistically significantly greater in those with malignant lesions in all groups, such as the radiological imaging features of the lesions, fine/core needle aspiration biopsy results, and the final pathology. The lesion size, BMI, smoking habit, and family history of BC were also more frequent in the malignant group. The rate of sports activity was lower in the malignant groups. The number of pregnancies and the total breastfeeding time were smaller and lower, respectively, in the benign groups, possibly due to the lower average age of the patients. The use of HRT showed no effect on the benign and malignant lesions. Thus, it seems necessary to evaluate patients individually when evaluating PBLs. It is therefore recommended to evaluate PBLs together with $\mathrm{BC}$ risk factors.

Ethics Committee Approval: Ethical approval for this study was obtained with regard to the Ethical Principles for Medical Research Involving Human Subjects (the Helsinki Declaration) from the Local Ethics Committee of Van Yüzüncü Yıl University, Turkey with the registration number of 2019/05-09.

Informed Consent: Written informed consent was not recieved due to the retrospective nature of the study.

Peer-review: Externally-peer reviewed.

\section{Authorship Contributions}

Concept: O.T.; Design: O.T., R.E.; Supervision: O.T., S.E., Ü.H.İ.; Resources: A.R.K., A.Ö., F.A., S.B, İ.Ö., E.Ş.; Materials: S.B., İ.Ö., E.Ş.; Data Collection and/or Processing: O.T., S.B., Ü.H.İ., A.R.K., F.A.; Analysis and/or Interpretation: O.T., S.E., Ü.H.İ., A.Ö.; Writing Manuscript: O.T., R.E., S.E.; Critical Review: O.T., S.E.

Conflict of Interest: The authors declare no potential conflict of interests with respect to the research, authorship, and/or publication of this article.

Financial Disclosure: The authors received no financial support for the research, authorship, and/or publication of this article.

\section{References}

1. Salamat F, Niakan B, Keshtkar A, Rafiei E, Zendehdel M. Subtypes of benign breast disease as a risk factor of breast cancer: a systematic review and meta analyses. Iran J Med Sci 2018; 43: 355-364. (PMID: 30046203) [Crossref]

2. Degnim AC, Dupont WD, Radisky DC, Vierkant RA, Frank RD, Frost $\mathrm{MH}$, et al. Extent of atypical hyperplasia stratifies breast cancer risk in 2 independent cohorts of women. Cancer 2016; 122: 2971-2978. (PMID: 27352219) [Crossref]

3. Tamimi RM, Rosner B, Colditz GA. Evaluation of a breast cancer risk prediction model expanded to include category of prior benign breast disease lesion. Cancer 2010; 116: 4944-4953. [Crossref]

4. Ozmen V, Cantürk Z, Celik V, Güler N, Kapkaç M, Koyuncu A, et al. The book of breast disease, Turkish Federation of Breast Diseases Societies (TMHDF). Ankara: Gunes Publications; 2012: 153.

5. Degnim AC, Visscher DW, Berman HK, Frost MH, Sellers TA, Vierkant RA, et al. Stratification of breast cancer risk in women with atypia: a Mayo cohort study. J Clin Oncol 2007; 25: 2671-2677. (PMID: 17563394) [Crossref]

6. Kabat GC, Jones JG, Olson N, Negassa A, Duggan C, Gingsberg M, et al. A multi-center prospective cohort study of benign breast disease and risk 
of subsequent breast cancer. Cancer Causes Control 2010; 21: 821-828. (PMID: 2008454) [Crossref]

7. Erel S. Benign proliferative lesions of the breast and cancer risk. Arsiv 2010; 19: 155 (PMID: 20084540) [Crossref]

8. Renshaw AA, Cartagena N, Schenkman RH, Derhagopian RP, Gould EW. Atypical ductal hyperplasia in breast core needle biopsies correlation of size of the lesion, complete removal of the lesion, and the incidence of carcinoma in follow-up biopsies. Am J Clin Pathol 2001; 116: 92-96. (PMID: 11447758) [Crossref]

9. Cleary MP, Grossmann ME. Minireview: Obesity and breast cancer: the estrogen connection. Endocrinology 2009; 150: 2537-2542. (PMID: 19372199) [Crossref]

10. Reeves GK, Pirie K, Beral V, Green J, Spencer E, Bull D, et al. Cancer incidence and mortality in relation to body mass index in the Million Women Study: cohort study. BMJ 2007; 335: 1134. (PMID: 17986716) [Crossref]

11. Key TJ, Appleby PN, Reeves GK, Roddam A, Dorgan JF, Longcope C, et al. Endogenous Hormones Breast Cancer Collaborative Group. Body mass index, serum sex hormones, and breast cancer risk in postmenopausal women. J Natl Cancer Inst 2003; 95: 1218-1226. (PMID: 12928347) [Crossref]

12. Terry MB, Zhang FF, Kabat G, Britton JA, Teitelbaum SL, Neugut AI, et al. Lifetime alcohol intake and breast cancer risk. Ann Epidemiol 2006; 16: 230-240. (PMID: 16230024) [Crossref]

13. Eliassen AH, Colditz GA, Rosner B, Willett WC, Hankinson SE. Adult weight change and risk of postmenopausal breast cancer. JAMA 2006; 296: 193-201. (PMID: 16835425) [Crossref]

14. Enger SM, Ross RK, Henderson B, Bernstein L. Breastfeeding history, pregnancy experience and risk of breast cancer. Br J Cancer 1997; 76: 118-123. (PMID: 9218743) [Crossref]

15. Lissowska J, Brinton LA, Zatonski W, Blair A, Bardin-Mikolajczak A, Peplonska B, et al. Tobacco smoking, NAT2 acetylation genotype and breast cancer risk. Int J Cancer 2006; 119: 1961-1969. (PMID: 16721725) [Crossref]

16. Al-Delaimy WK, Cho E, Chen WY, Colditz G, Willet WC. A prospective study of smoking and risk of breast cancer in young adult women. Cancer Epidemiol Biomarkers Prev 2004; 13: 398-404. (PMID: 15006915) [Crossref]
17. Lynch BM, Neilson HK, Friedenreich CM. Physical activity and breast cancer prevention. Recent Results Cancer Res 2010: 186; 13-42. (PMID: 21113759) [Crossref]

18. Dupont WD, Parl FF, Hartmann WH, Brinton LA, Winfield AC, Worrell JA, et al. Breast cancer risk associated with proliferative breast disease and atypical hyperplasia. Cancer 1993; 71: 1258-1265. (PMID: 8435803) [Crossref]

19. Fitzgibbons P, Henson DE, Hutter RV. Benign breast changes and the risk of subsequent breast cancer: an update of the 1985 consensus statement. Cancer Committee of the College of American Pathologists. Arch Pathol Lab Med 1998; 122: 1053-1055. (PMID: 9870852) [Crossref]

20. Goehring C, Morabia A. Epidemiology of benign breast disease, with special attention to histologic types. Epidemiol Rev 1997: 19; 310-327. (PMID: 9494790) [Crossref]

21. Nomura A, Comstock GW, Tonascia JA. Epidemiologic characteristics of benign breast disease. Am J Epidemiol 1977; 105: 505-512. [Crossref]

22. Hsieh CC, Walker AM, Trapido EJ, Crosson W, MacMahon B. Age at first birth and breast atypia. Int J Cancer 1984; 33: 309-312. (PMID: 6862681) [Crossref]

23. Dupont WD, Page DL. Risk factors for breast cancer in women with proliferative breast disease. N Engl J Med 1985; 312: 146-151. (PMID: 3965932) [Crossref]

24. Chlebowski RT, Hendrix SL, Langer RD, Stefanick ML, Gass M, Lane $\mathrm{D}$, et al. Influence of estrogen plus progestin on breast cancer and mammography in healthy postmenopausal women: the women's health initiative randomized trial. JAMA 2003; 289: 3243-3253. (PMID: 12824205) [Crossref]

25. Beral V. Million Women Study Collaborators. Breast cancer and hormone-replacement therapy in the million women study. Lancet 2003; 362: 419-427. (PMID: 12927427) [Crossref]

26. Hankinson SE, Colditz GA, Manson JE, Willett WC, Hunter DJ, Stampfer MJ, et al. A prospective study of oral contraceptive use and risk of breast cancer. Cancer Causes Control 1997; 8: 65-72. (PMID: 9051324) [Crossref]

27. Marchbanks PA, McDonald JA, Wilson HG, Folger SG, Mandel MG, Daling JR, et al. Oral contraceptives and the risk of breast cancer. N Engl J Med 2002; 346: 2025-2032. (PMID: 12087137) [Crossref] 